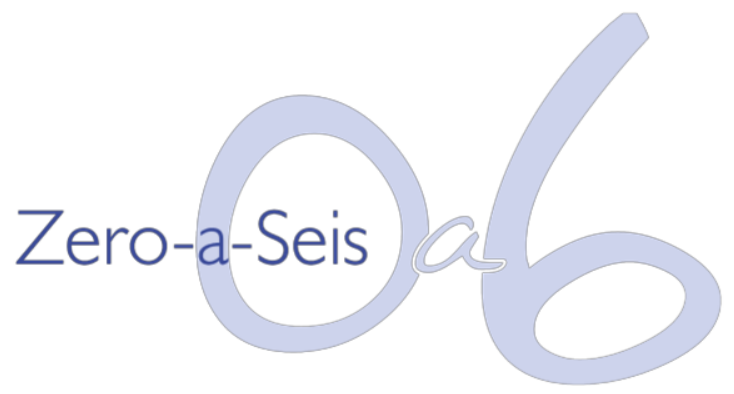

\title{
PROFESSORES HOMENS NA EDUCAÇÃO INICIAL: UM ESTUDO DE CASO EM UMA INSTITUIÇÃO DE EDUCAÇÃO INFANTIL COLOMBIANA ${ }^{1}$ \\ Male teachers in Early Education: a case study in a Colombian Early Childhood Education
}

\author{
Joaquim RAMOS \\ Doutor em Educação pela Universidade Federal de \\ Minas Gerais - Doutorado Latino-Americano \\ Professor da Rede Municipal de Educação de Belo \\ Horizonte e da Rede Estadual de Minas Gerais \\ joaquimramos2@yahoo.com.br \\ https://orcid.org/0000-0002-3829-6877 (c)
}

\author{
Maria de Fátima Cardoso GOMES \\ Doutora em Educação \\ Professora Titular \\ Faculdade de Educação \\ Universidade Federal de Minas Gerais \\ mafacg@gmail.com \\ https://orcid.org/0000-0002-6881-3193
}

A lista completa com informações dos autores está no final do artigo

\begin{abstract}
RESUMO
O artigo trata da atuação de professores do sexo masculino em uma instituição de Educação Inicial da Colômbia e, à luz das teorias de gênero, buscou compreender as representações de masculinidades e feminilidades que emergem da percepção de homens e mulheres sobre a docência masculina nesta etapa educacional. A investigação foi realizada de agosto a dezembro de 2017 e os dados foram produzidos por meio de entrevistas em profundidade com quatro docentes (dois professores e duas professoras). As entrevistas evidenciam que as relações dos professores homens com as crianças são desprovidas de preconceitos ou interdições, no entanto, as análises apontam que o trabalho desses profissionais é distinto daquele realizado pelas professoras e as especificidades de gênero que se constituem no espaço institucional acarretam tensões e ambivalências.
\end{abstract}

PALAVRAS-CHAVE: Professores homens; Educação Infantil; Colômbia.

\section{ABSTRACT}

The article deals with the performance of male teachers in an institution of Early Education in Colombia and, in the light of gender theories, sought to understand the representations of masculinities and femininities that emerge from the perception of men and women about male teaching in this educational stage. The investigation was carried out from August to December 2017 and the data were produced through interviews with four teachers (two male teachers and two female teachers). The interviews show

${ }^{1}$ Os termos Educação para a Primeira Infância e Educação Inicial são nomenclaturas utilizadas na Colômbia para se referir à educação das crianças de zero a cinco anos de idade, no campo da política nacional "De cero a siempre". 
that the relationships between male teachers and the children are free from prejudice or interdiction, however, the analyzes indicate that the work of these professionals is different from that performed by female teachers and the gender specificities that are constituted in the institutional space cause tensions and ambivalences.

KEYWORDS: Male teachers; Early Childhood Education; Colombia.

\section{INTRODUÇÃO}

Produzido a partir de dados provenientes de um estudo realizado em nível de doutorado² (RAMOS, 2018), o artigo objetiva analisar os limites e possibilidades de atuação de homens na docência com crianças pequenas em instituição de educação infantil Colombiana. Buscamos, nesse sentido, ampliar as reflexões realizadas no âmbito da tese de doutorado do primeiro autor com vistas a aprofundar a questão da docência masculina em creches e pré-escolas, a partir de observação participante e entrevistas com os docentes de uma instituição colombiana ${ }^{3}$.

O primeiro autor - que também desenvolveu a pesquisa de campo - acompanha a produção acadêmica brasileira sobre homens na docência com crianças pequenas há mais de 10 anos e, assim, em outro trabalho acadêmico (RAMOS, 2011), aprofundou esse assunto e constatou um reduzido número de pesquisas sobre a presença de professores do sexo masculino em creches e pré-escolas (CRUZ, 1998; SAYÃO, 2005; FERREIRA, 2008). Contudo, mais recentemente, especialmente na última década, houve um crescimento considerável de estudos sobre as atividades desenvolvidas por docentes do sexo masculino em instituições brasileiras de Educação Infantil (PEREIRA, 2012; SILVA, 2013; SILVA, 2014; LOPES, 2015; SOUZA, 2015; MORENO, 2017; SILVA E VELOSO, 2018; SILVA E RABELO, 2019, dentre outros).

Apesar do avanço dessa produção acadêmica nacional, há pouca discussão sobre a docência masculina em outros contextos idiomáticos, de maneira que pouco sabemos sobre os percursos e percalços vivenciados por professores homens na docência em creches e pré-escolas em outros países. Sendo assim, a pesquisa de doutorado conduziu-nos na busca pela compreensão das percepções de professores (e também de professoras) que atuam nas ações de cuidado e educação destinados às crianças de

\footnotetext{
2 Trata-se de pesquisa vinculada ao Doutorado Latino-Americano, do Programa de Pós-Graduação em Educação, da Faculdade de Educação da UFMG e, como exigido pelas normas do referido Doutorado, a pesquisa deveria ser realizada em, no mínimo, dois países da América Latina. Em decorrência das condições de acesso e permanência no campo de pesquisa, a nossa opção foi realizar a investigação em Bogotá, na Colômbia.

${ }^{3}$ Para maior fluidez na leitura, optamos em não utilizar as flexões de gênero que demarcam as diferenciações entre o masculino e o feminino.
} 
cinco anos de idade em uma instituição de Educação Infantil colombiana, sobre as possibilidades e restrições em termos de atuação profissional para docentes do sexo masculino.

Nesse sentido, a escrita desse artigo buscou dialogar - à luz das teorias de gênero - com a seguinte questão: como os professores homens que atuam em uma instituição de Educação Infantil colombiana percebem a própria presença em espaços de educação e cuidados de crianças pequenas? Dessa questão, desdobram-se outras de igual relevância para comporem as análises do mesmo estudo, pois sendo o gênero um conceito relacional, sentimos necessidade de indagar das professoras como elas percebem o trabalho realizado pelos homens que com elas partilham os cuidados e educação de crianças de cinco anos de idade, na mesma instituição? Como mulheres e homens percebem e vivenciam as relações de gênero no âmbito da docência da educação infantil? Quais as representações de masculinidades e de feminilidades que emergem e são atualizadas pela percepção de homens e mulheres sobre a docência masculina na Educação Infantil colombiana?

Para dialogar com essas questões, selecionamos excertos de entrevistas realizadas em profundidade com quatro docentes do Instituto Pedagógico Lewis Carroll ${ }^{4}$ e será esse o material de base para as nossas análises. Como afirmam Lüdke e André (2014), as entrevistas representam uma das principais técnicas de trabalho em Ciências Sociais e cumprem importante papel em atividades científicas e outras atividades humanas. Assim, a relação que se cria nessa forma de geração de dados é de interação, por permitir uma atmosfera de influência recíproca entre quem pergunta e quem responde as questões (LÜDKE e ANDRÉ, 2014. p. 38). As entrevistas permitem, ainda, a captação imediata e corrente das informações desejadas, praticamente com qualquer tipo de informante e sobre os mais variados tópicos, possibilitando tratar de assuntos de natureza pessoal e íntima, ao mesmo tempo. Essa técnica propicia condições de o pesquisador enveredar por temas de natureza complexa e de escolhas nitidamente

\footnotetext{
4 Quanto ao número de sujeitos participantes da pesquisa: em Belo Horizonte, na Escola Bartolomeu Campos de Queirós, além do professor José, único professor do sexo masculino exercendo a docência nessa instituição, participaram da pesquisa as duas professoras-referência das turmas, uma professora de apoio e a coordenadora. Já na Colômbia, na Escola Maternal Paulo Freire, participaram: o professor de música, um estagiário, duas professoras e a diretora. No Instituto Pedagógico Lewis Carroll, a pesquisa contou com a participação de vários e várias docentes: de Teatro, de Música, de Educação Física, de Informática, além das duas professoras titulares das turmas. Sendo assim, em função do formato desse artigo, não foi possível apresentar todos esses sujeitos e por esse motivo, optamos em fazer um recorte, trazendo apenas excertos de quatro docentes, a saber: Humberlet, Fernando Rivera, Sony e Mary - todos esses nomes são fictícios e foram escolhidos pelos próprios docentes).
} 
individuais, contribuindo, dessa maneira, para o aprofundamento de pontos levantados por outros recursos metodológicos de geração de dados (LÜDKE e ANDRÉ, 2014).

As entrevistas foram realizadas ao longo do segundo semestre de 2017, durante o tempo de planejamento do trabalho pedagógico, em local acordado previamente com os docentes e todos os participantes assinaram os termos de consentimento livre e esclarecido. As entrevistas foram gravadas em dispositivos audiovisuais e transcritas em espanhol para serem utilizadas no processo de composição da tese e do presente artigo. Cada docente foi entrevistado individualmente, em espaços reservados da própria instituição, em dias e horários previamente acordados.

\section{A EDUCAÇÃO DA PRIMEIRA INFÂNCIA NO SISTEMA EDUCATIVO COLOMBIANO: UMA MIRADA NOS DOCUMENTOS OFICIAIS}

O sistema educativo colombiano considera a educação como um direito do cidadão e uma prioridade do governo, sendo regido pela Constituição de 1991 e pela Lei Geral da Educação (Ley no 115, de 1994). De acordo com essa legislação, "todos os colombianos têm direito a aceder à educação para o seu desenvolvimento pessoal e para o benefício da sociedade". Desta maneira, a educação obrigatória atualmente é de 10 anos (dos 5 aos 15 anos de idade) e se divide em quatro etapas: a Educação Inicial e Atenção Integral à Primeira Infância (EIAIPI) que inclui atendimento para as crianças desde o nascimento até os 6 anos de idade $^{5}$ e a educação básica (primária e secundária).

Nos últimos anos, a Colômbia avançou em muitos aspectos relacionados à Educação da Primeira Infância e buscou construir um documento basilar com o objetivo de ampliar a discussão sobre o trabalho pedagógico. Tais avanços apresentam sintonia com o processo de construção de novas referências no campo da política educacional brasileira, inauguradas com a Lei de Diretrizes e Bases da Educação Nacional, LDBEN (BRASIL, 1996), que, dentre outras provisões insere creches e pré-escolas no campo educacional e passa a considerá-las como a primeira etapa da Educação Básica. Essas semelhanças são evidenciadas no documento colombiano na busca pela promoção, de modo intencional, do desenvolvimento integral das crianças, começando pelo reconhecimento de suas características e particularidades e dos contextos em que vivem, favorecendo, dessa maneira, as interações geradas, enriquecidas pelas

${ }^{5}$ Equivalente à educação infantil no Brasil. 
experiências pedagógicas e práticas de cuidados. Dentre outros aspectos, o documento que embasa a proposta da educação inicial colombiana assegura que

\begin{abstract}
Na educação inicial, as meninas e os meninos aprendem a conviver com os outros seres humanos, a estabelecer vínculos afetivos com seus pares e com os adultos externos à própria família, a relacionar-se com o ambiente natural, social e cultural; a conhecer-se, a ser mais autônomos, a desenvolver confiança em si mesmos, a ser cuidados e a cuidar dos demais, a sentir-se seguros, partícipes, ouvidos, reconhecidos, a fazer e responder perguntas, a indagar e formular explicações próprias sobre o mundo em que vivem, a descobrir diferentes formas de expressão, a decifrar as lógicas que fazem mover a vida, a solucionar problemas do cotidiano, a decifrar as lógicas do movimento que oferece seu corpo, a apropriar-se e fazer seus, os hábitos de vida saudável, a enriquecer a sua linguagem e construir sua identidade em relação com sua família, sua comunidade, sua cultura, seu território e seu país (COLÔMBIA, 2014 documento $n^{\circ} 20$ - livre tradução).
\end{abstract}

Percebe-se nesse documento que a criança é compreendida como sujeito produzido na cultura ao passo em que é por ela produzida - compreensão muito próxima da concepção de criança celebrada pelas Diretrizes Curriculares Nacionais para a Educação Infantil, DCNEI, que concebe a criança como cidadã de direitos que produz cultura nas diversas interações e relações estabelecidas com seus pares e com os adultos (BRASIL, 2009). A lei colombiana ainda ressalta direitos de aprendizagem das crianças, tais como: direito a conviver, expressar-se, conhecer-se - também previstos no texto da Base Nacional Comum Curricular para a Educação Infantil, BNCC (BRASIL, 2017).

No projeto pedagógico do Instituto Pedagógico Lewis Carroll está previsto que as crianças devem se constituir enquanto sujeitos sociais, com autonomia, desenvolvimento pleno, respeito à individualidade e ao coletivo, com relações fraternas entre elas próprias e o mundo exterior. Da mesma maneira, a instituição destaca que o aprendizado e o desenvolvimento adquiridos durante os primeiros anos de vida, deixam marcas profundas para toda a vida. Portanto, as experiências pedagógicas típicas da educação inicial se caracterizam por sua intencionalidade e devem responder a uma perspectiva de inclusão e equidade para promover e reconhecer a diversidade étnica, cultural, social e das características geográficas e socioeconômicas dos contextos em que vivem as meninas, os meninos e suas famílias.

Do mesmo modo, o "Documento del nível preescolar", de 2014, elaborado pelos docentes do Instituto Pedagógico Lewis Carroll, ressalta que ela foi inaugurada em 1934, sendo uma das primeiras instituições educativas para crianças do país.

Em seu histórico apresenta o enquadramento do pré-escolar, desde a fundação, aos princípios da escola ativa, com notória inspiração nas propostas desenvolvidas por Fróbel, Waldorf, Decroly e Maria Montessori. Assim, as crianças participam de atividades 
diversificadas como educação física, educação musical, teatro, informática, jogos estratégicos, jogos matemáticos e arte, com ênfase especial na iniciação musical. Se por um lado, a política de educação infantil colombiana apresenta aproximações com aquela produzida no Brasil, por outro, a organização cotidiana distancia tais ordenamentos jurídicos. Aqui há uma diferenciação: se as DCNEI pensam a criança como centro do processo pedagógico, já a EI colombiana parte de conteúdos e não da formação dos pequenos, apesar de ressaltar a importância de suas experiências para a aprendizagem de meninos e meninas.

Esse mesmo documento (IPLC, 2014) considera que o fazer pedagógico do préescolar se centra na ludicidade e considera o respeito pela personalidade e aceitação das diferenças individuais, considerando os processos de aprendizagens, as diferenças de idades e as dificuldades apresentadas pelas crianças ao longo de seu período escolar. No plano da cultura e da vida social, um dos quesitos defendidos é que a criança inicie a sua participação e colaboração com os adultos e com os pares, em distintas atividades e que o respeito, a honestidade, a tolerância, a solidariedade sejam práticas constantes e diárias.

Em síntese, é nesse contexto de relações, historicamente ocupado por crianças e mulheres que os docentes homens colombianos que optaram atuar profissionalmente com os cuidados e a educação de crianças pequenas se inserem. Tal inserção promove diversas percepções sobre os limites e as possibilidades de atuação concernentes ao trabalho docente na educação da primeira infância colombiana.

\section{SOB A ÉGIDE DA PERCEPÇÃO: ALGUNS APORTES TEÓRICOS PARA PENSAR A PRESENÇA DE PROFESSORES HOMENS NA EDUCAÇÃO INFANTIL COLOMBIANA ${ }^{6}$}

Como anunciado, o artigo objetiva compreender como os professores homens que atuam em uma instituição de Educação Infantil colombiana percebem, à luz das teorias de gênero, a própria presença nesse contexto. Além de buscar compreender, sob a ótica das professoras, como esses homens são percebidos nas ações relacionadas à educação de crianças pequenas. Neste sentido, o conceito de percepção se impôs como ferramenta analítica para a compreensão dessas especificidades relacionadas aos

\footnotetext{
${ }^{6}$ Considerando as dificuldades encontradas para acessar as pesquisas sobre a educação de crianças, em espaços institucionais, na Colômbia, mesmo o primeiro autor desse artigo tendo retornado a Bogotá, exclusivamente para este fim, não logrou êxito no empreendimento, mesmo consultando bibliotecas e universidades de ponta como a biblioteca da Pontfifícia Universidad Javeriana; biblioteca pública Vírgilio Barco, biblioteca da Universidad Pedagógica Nacional e biblioteca Luis Angel Arango.
} 
docentes colombianos em seus modos de operacionalizar as relações de gênero, tendo como fio condutor a presença de professores do sexo masculino na instituição pesquisada.

A lógica que orienta nossa percepção, diz respeito a nós mesmos e à relação subjetiva assumida como humanos, pois nos sentimos e nos percebemos no tempo e no espaço, mas também diz da nossa percepção sobre o outro. Neste sentido, cabe-nos indagar: afinal, como funciona a percepção humana? Que relação ela estabelece com as sensações? Entendemos que sentir é algo ambíguo, pois o sensível é, ao mesmo tempo, a qualidade que está no objeto e o sentimento interno que nosso corpo possui das qualidades sentidas. Portanto, a percepção torna o sujeito indissociável do objeto percebido.

Para Marilena Chauí (2000), a sensação e a percepção dependem do sujeito do conhecimento e a coisa exterior é apenas a ocasião para ter a sensação ou a percepção. Deste modo, a autora defende que "sentir e perceber são fenômenos que dependem da capacidade do sujeito para decompor um objeto em suas qualidades simples (a sensação) e de recompor o objeto como um todo, dando-lhe organização e interpretação (a percepção)" (CHAUÍ, 2000, p.151).

Por isso, na sensação "sentimos" qualidades pontuais, dispersas, elementares e, na percepção, "sabemos" que estamos tendo sensação de um objeto que possui as qualidades sentidas por nós. Esse entendimento nos permitiu perceber por meio das entrevistas com os docentes do Instituto Lewis Carroll que a atuação de homens na docência de crianças "é sempre uma experiência dotada de significação, isto é, o percebido é dotado de sentido e tem sentido em nossa história de vida, fazendo parte de nosso mundo e de nossas vivências" (CHAUÍ, 2000, p.154).

Assim como ocorre com tantas profissões, a profissão docente é marcada pela singularidade e heterogeneidade de seus profissionais. Nesse sentido, requisitos relacionados à origem social, nível de formação, experiência, gênero e dedicação, dentre outros, são constitutivos das subjetividades que envolvem o fazer docente. Essas categorias, como parte da identidade humana, representam aspectos importantes para a compreensão dos modos de ser professor/professora em qualquer etapa de educação. $\mathrm{Na}$ Educação Inicial colombiana, assim como ocorre no Brasil, pelo seu histórico de atividade majoritariamente feminina, os professores do sexo masculino ainda tendem a ocupar posições periféricas, conforme afirma Ramos (2011):

Ao ingressarem nas escolas, esses docentes homens são "naturalmente" encaminhados para as funções de apoio ou para as turmas de crianças maiores - 
que, normalmente, demandam menos ações relacionadas ao cuidado corporal. Nesse sentido, uma das principais constatações da dissertação é que, para além do período probatório exigido legalmente, todos os professores homens abordados na pesquisa necessitaram de um tempo para demonstrarem as competências e as habilidades com a educação e o cuidado das crianças pequenas matriculadas nas instituições públicas de educação infantil do município - categorizado, aqui, como período comprobatório (RAMOS, 2011, p. 9).

Além disso, o ingresso, a permanência e o desenvolvimento das ações pedagógicas, no cotidiano de professores homens em espaços de educação e cuidado de crianças, ainda são, normalmente, marcados por estranhamentos, preconceitos e discriminação. De modo mais acentuado, percebemos em nossa investigação na Colômbia que, apesar de serem aceitos e tidos como sujeitos importantes na formação das crianças, esses professores do sexo masculino constituem, numericamente, uma pequena minoria no exercício da docência. Esses professores executam funções com as crianças mais velhas e, no geral, em espaços abertos ou que permitem serem observados por outros adultos.

Déborah Tomé Sayão (2005), em estudo sobre a presença de homens na educação infantil, apresenta algumas pistas que nos permitem compreender o quão importante é a inserção e a permanência de profissionais do sexo masculino na docência de crianças, contudo, essa pesquisadora defende que essa inserção para ser realmente significativa, é necessário que homens e mulheres rompam com a fixidez de papéis e funções destinados a cada gênero, pois

Os modelos socialmente construídos de mulheres, cuidadoras e homens, provedores, talvez tenham contribuído para gerar nas profissionais a aposta de que os docentes, não dariam conta do recado, tendo em vista que são elas que historicamente e desde a infância aprendem como cuidar (SAYÃO, 2005, p.177).

Na perspectiva de Sayão (2005), parece haver práticas sociais comumente exercidas por mulheres que legitimam o argumento da feminilidade como características inatas de seres supostamente que, do ponto de vista biológico, estariam "programadas" para cuidar e educar as crianças. Para a autora, à menina se ensina o trato com o cuidado de pessoas e ao oferecer-Ihe protótipos de gente, em forma de bonecas, pretende-se com isso que desde pequena, ela comece a "tomar" conta do espaço doméstico, enquanto os meninos aprendem, desde a mais tenra idade, que dentre outras obrigações, o provimento da casa é de sua responsabilidade. É necessário que o menino entenda o papel social a ele reservado, como futuro "chefe de família" e, claro, tais ensinamentos irão reverberar durante toda a sua vida. Para Louro (1999), 
tais afirmações estão carregadas de representações simbólicas de masculinidade e feminilidade e são constituintes da realidade, já que figuram no plano da cultura e, desse modo, acabam se consolidando como "a verdade".

Percebe-se que, ao inserirem-se nas práticas de cuidado e educação, esses profissionais nem sempre têm a possibilidade de atuar de modo pleno na profissão. Em outras ocasiões, eles próprios - fundamentados em discursos e representações de senso comum - limitam seu campo de atuação profissional para se precaverem do que "os outros podem pensar", conforme será destacado em nossas análises. Assim, por serem alvo de suspeita por parte de diferentes segmentos da comunidade educacional, esses professores, em muitos casos, se restringem em exercerem aquelas funções que os distanciam dos cuidados, em especial, aqueles relacionados à higiene com os corpos das crianças. Tal ocorrência, bastante comum também na Educação Infantil brasileira, foi tratada da seguinte maneira porRamos (2017):

Percebe-se que não sem razão, vários professores, ao tomarem posse em cargos de educador infantil, foram encaminhados para as funções nas quais atuariam sob a vigilância constante de outros profissionais. Ou seja, eram colocados na função de professor do apoio, na função de professor responsável pela "educação física", pelas oficinas de artes, de informática ou qualquer outra linguagem nas quais existissem menor demanda de cuidados e de toques físicos (RAMOS, 2017, p.125).

Ao discorrer sobre essas mesmas questões, Sayão (2005) assegura que na Educação Infantil, não somente no Brasil, mas em vários outros países, as atividades docentes constituem espaço de atuação profissional ocupado, principalmente, por mulheres, por se basear em atributos de uma função social cuja gênese atrela-se ao feminino. Deste modo, não representa novidade o fato de os professores homens investigados na Colômbia, não exercerem os cargos de referência das turmas (ou a titularidade das turmas). Ou seja, sob diferentes percepções, as professoras atribuem certo grau de importância à presença de professores homens em suas turmas, mas são as próprias professoras que continuam ocupando a titularidade dessas turmas, conforme será analisado na próxima seção, por meio do material empírico.

\section{A PERCEPÇÃo de PROfessoras e PROfEsSORES SObRe A PRESENÇA de DOCENTES HOMENS NA EDUCAÇÃO DA PRIMEIRA INFÂNCIA NO INSTITUTO PEDAGÓGICO LEWIS CARROLL}


No processo de produção do material empírico, as falas dos sujeitos da pesquisa denotam, inicialmente, que por parte da comunidade escolar colombiana, inexistiam restrições em relação à presença de homens na docência das crianças. No plano discursivo, esses professores são aprovados e considerados profissionais necessários e importantes no desempenho das atividades docentes. No entanto, em nossas análises percebemos que, ao contrário do que esses argumentos apontavam, a presença de professores do sexo masculino não era desprovida de ressalvas, seja em relação à prática pedagógica, seja em relação à forma de interagir com meninas e meninos. Além disso, em nossos procedimentos de pesquisa de campo, observamos tratamento diferenciado e especificidades de gênero no espaço institucional em relação aos dois professores, o que acarretava, em variados momentos, foco de tensionamento, discussão e ambivalência.

Assim, analisaremos excertos de entrevistas de dois professores homens que atuavam no Instituto Pedagógico Lewis Carroll e, em perspectiva relacional, apresentamos as percepções de duas professoras que com esses docentes do sexo masculino partilhavam, profissionalmente, naquele contexto, as ações de cuidado e educação destinados às crianças de cinco anos de idade.

\section{As percepções do professor de música Fernando Rivera?}

Em 2017, o professor Fernando Rivera atuava com crianças pequenas desenvolvendo atividades de música no Instituto Pedagógico Lewis Carroll. Para ele, além de a educação de crianças pequenas na Colômbia constituir, historicamente, um espaço feminino de atuação profissional, há um papel social reservado à família em âmbito doméstico que é próprio do sexo masculino. Em suas palavras, se a criança não conta com uma referência masculina em casa, a escola deve contribuir e repassar para as gerações que chegam ao mundo um modelo de homem:

\footnotetext{
Historicamente siempre ha sido um matriarcado en esa etapa de la formación, yo creo que si es muy importante y marca certa diferencia, por ejemplo, hay algunos niños que familiarmente no cuentan con una referencia masculina, entonces, muchas veces un profesor hombre que ocupe alguno de los campos de formación en la escuela se convierte en un modelo para ellos, en ciertos aspectos respecto a la masculinidad, al comportamento (Entrevista concedida em 20/10/2017).
}

\footnotetext{
${ }^{7}$ Reiteramos que os nomes dos professore e das professoras foram alterados para respeitar o anonimato acordado.
} 
Além disso, em seu entendimento, para atuar na docência de crianças, o professor sendo do sexo masculino deve apresentar uma dupla especificidade: a de ser modelo de homem e a de cumprir uma atribuição que, em princípio, cabe à família. Para ser referência, deve apresentar um comportamento próprio da masculinidade - como ser homem (ou ser mulher) fosse orientado por modelos culturais universais, muitas vezes, tidos como formas hegemônicas de vivenciar a masculinidade e também a feminilidade (CONNELL, 1995), o que de certa maneira, tal compreensão sobre a função social que escapa das atribuições diretas da docência de criança, apresentada pelo professor Rivera, estabelece estreita relação com o senso comum.

Nos termos do professor Fernando Rivera, há um padrão de normalidade a ser observado para não "fugir do modelo de homem". Ainda que subliminarmente, esta afirmação apresente a defesa de padrões comportamentais heteronormativos. Por sabermos que a instituição escolar é um espaço social que contribui para a produção, reprodução e atualização dos parâmetros da heteronormatividade, como dispositivos (discursos, valores, práticas) por meio dos quais a heterossexualidade é instituída e vivenciada como única [ou principal] possibilidade natural e legítima de expressão (JUNQUEIRA, 2015, p.224) é que mesmo não explicitando, subentende-se que a compreensão desse professor ratifica a existência de um "único" jeito de a instituição escolar normatizar e tomar como regra a heterossexualidade para todos os corpos e comportamentos. Assim, nessa afirmação há implicações envolvendo o modelo hegemônico de masculinidade dentro da condição binária e restritiva que engendra a presença do professor homem em um único aspecto da constituição humana.

Para Junqueira (2015), há um conjunto de padrões que regula não apenas a sexualidade, mas também o gênero e por isso, ele entende que:

\begin{abstract}
As disposições heteronormativas voltam-se a naturalizar, impor, sancionar, promover e legitimar uma única sequência sexo-gênero-sexualidade: a [disposição] centrada na heterossexualidade e rigorosamente regulada pelas normas de gênero (Butler, 2003), as quais, fundamentadas na ideologia do dimorfismo sexual, agem como estruturadoras de relações sociais e produtoras de subjetividades e encontram, no campo da sexualidade reprodutiva, um dos mais poderosos argumentos para justificar tanto as teses naturalizantes acerca das identidades sexuais e de gênero quanto as violações dos direitos das pessoas que pareçam delas destoar (JUNQUEIRA, 2015, p.224) ${ }^{8}$.
\end{abstract}

\footnotetext{
${ }^{8}$ De maneira complementar, vale a pena acrescentar que aprender sobre nossos direitos e ensinar as crianças a exercitá-las é aprender a ver a nós mesmos e aos outros como seres capazes, certamente, mas também como seres vulneráveis que precisam de cuidados mútuos (Ruiz y Prada, 2020).
} 
Na entrevista com o professor Fernando Rivera, elencamos, dentre outros, dois aspectos que merecem destaques: o primeiro relaciona-se à ideia de que "ao se propor trabalhar com as crianças pequenas, o professor do sexo masculino deve representar um modelo de comportamento, desde a forma de manejar o corpo, até o jeito de se comunicar, pois para as crianças, essa vivência contribuirá para enriquecer diferentes aprendizagens e sentimentos". Ou seja, ele defende o dito "normal" como um princípio para ser professor de crianças pequenas, corroborando a narrativa de Junqueira (2015), acima. O segundo aspecto a ser destacado, diz respeito aos sentidos que ele apresenta sobre o modo de as professoras perceberem a presença de um homem atuando na docência das crianças. Tal compreensão foi afirmada nos seguintes termos pelo professor Rivera:

La profesora decia que es refrescante para ella que tu como hombre llegues y les des clase, es positivo que tu como hombre tengas un acercamiento a los niños, para que ellos también se oxigenen un poco en su clase de música. Entonces, si, yo creo que en ese sentido yo creo que si, es algo muy valioso (Entrevista concedida em 20/10/2017).

Entendemos que para além do reconhecimento das professoras sobre a importância da presença de homens na docência de crianças, urge que a educação em qualquer uma de suas etapas e independentemente do gênero do docente - precisa ter como princípio, o propósito de contribuir com o desenvolvimento humano. Deste modo, não basta ser homem ou ser mulher, é necessário mais do que as implicações relacionadas ao gênero para representar um modelo de comportamento. Do mesmo modo, é insuficiente a demonstração de que o sujeito que opta pela docência deve integrar uma masculinidade hegemônica. A ideia contida em "es positivo que tu como hombre tengas una cercamiento a los niños para que ellos también se oxigen em un poco en suclase de música" vincula-se a outros fatores internos da instituição que extrapolam apenas a questão relacionada à identidade de gênero do professor ou da professora. Obviamente, essa observação também poderia ser interpretada como a necessidade de a educação infantil ter diferentes tipos de educadores, não apenas mulheres, para que meninos e meninas pudessem conviver, na escola, com professores de ambos os sexos, fazendo ressoar, desta maneira, o que ocorre, de modo efetivo, nas relações sociais e humanas.

Deste modo, para potencializar o sentido da ação pedagógica, a presença dos professores homens não deve ser apenas para oxigenar o cérebro das crianças ou servir de "refresco" para a professora titular. Essa afirmação serve para diminuir a importância das ações docentes desses profissionais, pois se o objetivo de "La clase de 
musica" é para esses fins, faz-se necessário, então, repensar a própria concepção da instituição escolar e o seu currículo. Como sabemos, a chave para o desenvolvimento de uma educação de qualidade não deve vincular-se à categoria gênero, mas de modo mais abrangente e necessária, é importante haver, por parte de todos os seus participantes, a compreensão da função social da instituição que se propõe educar crianças da pré-escola. Neste caso específico, outro aspecto importante a ser considerado é o papel da música na Educação da Primeira Infância, como parte integrante do desenvolvimento humano.

Outro aspecto das atividades docentes de homens relaciona-se às questões de abusos sexuais e do contato físico com as crianças. Assim, o professor Fernando Rivera reconhece a existência de docentes do sexo masculino que se excedem e cometem desrespeito com as crianças. Em seu entendimento, isso afeta quem não apresenta comportamento similar ou carrega algum tipo de perversão relacionada ao abuso sexual. Esse tipo de comportamento representa prejuízo para a classe. Em suas palavras:

\begin{abstract}
En mi país se han presentado algunas cosas que no son muy apropriadas en algunos professores hombres y que por eso, digamos, se ha generado cierto prejuicio de que ellos participen en la educación, sobre todo, en la educación inicial, y es que ha habido casos de abuso sexual, de irrespeto. Con el acercamiento a los niños al principio yo fuy muy restringido, tú sabes que los niños tienden a abrazar, son muy cariñosos, sí, esa es su manera de ser y de expresarse, entonces, al principio, digamnos que yo me generé ciertas restriciones por eso mismo, porque hay muchas personas que no ven eso com buenos ojos (Entrevista concedida em 20/10/2017).
\end{abstract}

Essa afirmação apresenta efeitos sobre a prática pedagógica cotidianamente desenvolvida por esse professor. Para realizar as atividades relacionadas à música com as crianças, ele levava consigo um violão e, assim, consciente das inúmeras restrições em relação ao toque corporal, a forma encontrada por ele para se precaver foi a de utilizar o próprio instrumento como escudo de proteção. Quando as crianças se aproximavam para cumprimentá-lo com abraços e toques, ele direcionava a alça do violão, oferecendo essa parte do instrumento para não precisar tocar nos corpos das crianças (e vice-versa). Com essa forma de defesa, adulto e crianças não se tocavam e essa parte do instrumento se transformava em extensão da mão do professor, como ele mesmo destacou:

Los niños se ponen muy contentos cuando te ven y quieren abrazarte y quieren saludarte y uno no todo el tiempo les puede hacer eso, porque eso también, en cierto modo, coarta su expresividad, entonces no, finalmente, yo opté porque ellos llegan, me saludan, entonces yo también los abrazo, yo uso mucho mi colgante, el de la guitarra, se convirtió en un mecanismo de comunicación com ellos, 
entonces, cuando yo quería restingir un poco el contacto, yo les decía: "dame la mano" y ellos me daban la mano y, de esa manera, digamos, no tenía ese acercamiento que muchas veces, lastimosamente, pueden generar malos entendidos (Entrevista concedida em 20/10/2017).

Em sua tese de doutoramento, Buss-Simão (2012) analisa a relação de proximidade entre as crianças com os seus pares e entre essas com os adultos e constata que as crianças, ao se colocarem próximas umas das outras e dos adultos, torna-se evidente a centralidade do corpo, do toque, do tato, do afeto. Contudo, a pesquisadora destaca que mesmo nas culturas latinas, em que as distâncias relativas são menores e as pessoas não se sentem desconfortáveis quando estão próximas umas outras, esses comportamentos causariam desconfortos, entre os adultos (BUSS-SIMÃO, 2012, p.156). Essa constatação da pesquisa de Buss-Simão estabelece relação com o comportamento do professor Rivera que, mais do que um sentimento de desconforto pela proximidade corporal com as crianças, ao restringir o toque, ele pratica uma ação preventiva "que muchasveces, lastimosamente, se puedengenerar malos entendidos". Os mal-entendidos a que o professor se refere são, em nosso entendimento, aqueles que, em sua perspectiva, poderiam, em princípio, gerar desconfianças de suas colegas do sexo feminino ou de qualquer outro adulto que estivesse observando, de modo descontextualizado, as expressões espontâneas de afeto das crianças em relação a ele.

Daniel Brailovsky (2013), ao investigar a questão da inserção de professores homens no contexto argentino, afirma que esses profissionais, ao desenvolver práticas pedagógicas direcionadas às crianças, principalmente aquelas que envolvem os cuidados destinados à higiene pessoal, tendem a levar em conta o que os outros (diretores(as), pais e familiares das crianças, dentre outros(as)) pensam sobre sua atuação. De acordo com o autor, questionamentos sobre a possibilidade de abusos sexuais com as crianças são ameaças fantasmagóricas que estruturam e condicionam suas experiências profissionais.

Para Brailovski (2013, p. 16-17) essa cena "temida os leva não apenas a trabalhar 'com La puerta de La clase abierta', mas a estabelecer alianças de proteção e garantia com as diretoras dos Jardins e a cultivar certos tipos de relacionamento com famílias das crianças", produzindo formas de evitar tais suspeitas. Ou seja, para evitar maus entendidos, ele escolhe uma maneira pessoal para se precaver e, claro, essa é uma ação que deve ser compreendida pela chave analítica das relações de gênero. No caso de nosso estudo, o professor Rivera tem necessidade de interagir com meninas e meninos, mas escolhe fazê-lo de maneira a não se comprometer frente aos olhares 
persecutórios que podem existir em seu entorno. Essa argumentação evidencia atravessamentos das relações de gênero marcados não apenas pela relação estabelecida com as crianças, mas pelo olhar das pessoas "de fora" que pode gerar mal entendido (BRAILOVSKY, 2013).

Ao ser indagado se em seu percurso na docência com crianças já havia sofrido algum tipo de discriminação ou de preconceito por parte da comunidade escolar, o professor Fernando Rivera afirmou que "não, nunca". Sendo assim, ele ainda destacou que tanto em seu país, de modo geral, quanto em instituições de Educação Inicial, mais pontualmente, o respeito às crianças é tomado como prioridade, ainda que haja casos de pedofilia e de desrespeito às crianças pequenas, todavia, destacou que em sua ação docente, na Educação Pré-Escolar, ele está tentando prosseguir, com a clareza de que há necessidade de se precaver.

Difícil explicar a afirmação do professor Rivera em relação ao fato de ele não ter sofrido discriminação ou preconceito no exercício de sua função docente, pois em vários momentos da entrevista, ele demonstra excessiva precaução, como por exemplo, ao afirmar que para afastar-se dos corpos das crianças utiliza o instrumento musical. Além disso, em seu entendimento, é preciso se policiar para evitar maus entendidos, uma vez que os pais estão sempre muito atentos. Afirmações como essas fornecem indícios de que há, por parte da comunidade escolar, desconfiança em relação à atuação de professores do sexo masculino. Essa pode ser uma das maneiras de explicar a exacerbada preocupação do professor Rivera em sua forma de se relacionar com as crianças. Deste modo, cabe-nos perguntar: isso realmente é apenas uma forma de se precaver e evitar danos futuros? Ou a comunidade escolar é, por excelência, preconceituosa em relação à presença de homens no espaço de educação e cuidados?

\section{AS PERCEPÇÕES DE HUMBERLET, O PROFESSOR DE ARTES CÊNICAS}

Além do trabalho com música desenvolvido pelo professor Fernando Rivera, as atividades relacionadas às artes cênicas estavam sob a responsabilidade do professor Humberlet que há 18 anos atuava na educação. Ele tem formação em Artes Cênicas pela Universidade de Antióquia, várias especializações em outras áreas, tais como: Comunicação, Arte Lírica, Planejamento Educacional e Ética. Assim, ao falar de sua trajetória profissional, ele demonstra orgulho por ter atuado em grupos de teatro, como ator e como escritor, com trabalhos produzidos para a televisão e com atuação na Escola Nacional de Artistas Infantis. 
Para Humberlet, o teatro é uma ferramenta que visa ampliar e potencializar outras linguagens, sendo que a partir dele, as crianças podem descobrir-se e desenvolver a corporalidade, descobrir que o gesto pode expressar e tornar-se consciência. Normalmente, os seres humanos possuem, desde o nascimento, de modo inconsciente, essas ferramentas. O teatro torna isso consciente, pois até mesmo no rosto da criança se vê expresso suas emoções internas e isso é parte fundamental da comunicação.

Em suas palavras, a Educação da Primeira Infância é um ofício diretamente relacionado às mulheres, mas isso não quer dizer que os homens não possam atuar como docentes de criança. Deste modo, para ele:

\begin{abstract}
Realmente, los géneros son diferentes y en eso tenemos que definir el hecho de que tradicionalmente la educación de la primera infancia había sido manejada por mujeres, no significa que los hombres, que entremos, tengamos que parecernos o tengamos que niverlarnos a la condición de la mujer, no, en la condición de hombre esta la parte paternal, la parte del hombre, eso es parte de la formación, porque los niños conviven también con hombres: su papá, su abuelo son hombres, cuando los hay, entonces, nosotros no podemos perder esa condición, debe ser más bien una ganancia y, efetivamente, los niños sienten más seguridad con uno, o sea, como que ellos ven reflejado que el hombre es un poco más fuerte, que los puede proteger, que los puede proteger a otro nível, de pronto, no tanto de consentir. Esperan más el consentimientoo de la mamá, verdade, porque es de la professora que se parece a la mamá, o sea, la relacionan con la mamá, pero al hombre lo ven un poco distanciado y eso es bueno, eso es bueno porque el hombre, pues le da otras líneas de aprendizaje, otra forma que permite que el niño vea reflejado su condición, vea en él a otro hombre, vea en él a otro un par, una referencia positiva (Entrevista concedida em 23/10/2017).
\end{abstract}

Essa mistura de atribuições familiares e domésticas com o campo profissional aparece em várias entrevistas, como uma ideia recorrente quando o assunto é trabalho docente com crianças pequenas. De igual maneira ocorreu no Brasil, pois desde o início da década de 1990, Carvalho reconhece que as professoras combinavam referenciais domésticos com atribuições relacionadas ao exercício do magistério. Essa autora afirma que

A domesticidade, a vida familiar e a criação dos filhos, que seriam os eixos tanto da socialização feminina quanto da vida da maioria das mulheres adultas em nossa sociedade, seriam levadas escola adentro fazendo com que, para as educadoras, "o exercício profissional na escola aparecesse como uma extensão de seu papel doméstico, de mãe e dona de casa, o que tem consequências sobre todo o funcionamento escolar (CARVALHO, 1999, p.15).

Cabe ressaltar que as falas do professor Humberlet apresentam, dentre outros fatores, alguns aspectos que merecem ser discutidos. O primeiro deles, diz respeito à mistura de papeis sobre a figura masculina, pois ao afirmar que a representação do professor tem relação com a figura paterna, há na afirmação, uma transferência indevida entre os papeis da família e da instituição de educação. Assim, ao afirmar que "en La 
condición de hombre esta la parte paternal", o professor evidencia um esvaziamento de uma das funções da instituição educativa que é a de considerar o professor como parte indissociável da esfera profissional. Posições assim, corroboram a desvalorização da profissão docente, pois como sabemos, a função paterna não se inscreve na carreira do magistério. Também é possível que o professor Humberlet queira enfatizar que a educação não apenas permite aprender conteúdo e desenvolver habilidades, mas também modelar os papéis de gênero.

Diferentemente da mistura entre o familiar e o profissional, em termos de valorização da carreira docente, há uma concepção sobre o trabalho do professor homem pautada na ideia da equidade social. Para Sayão $(2005$, p.16), isso é indício de que o envolvimento de um maior número de docentes homens na Educação Infantil aumentaria a opção de carreira para eles e contribuiria para que se desfizesse a imagem de que esta etapa inicial da educação seria um trabalho somente para as mulheres. Desta maneira, o ingresso de professores do sexo masculino nesta etapa inicial da educação, alteraria a imagem da profissão, acarretando uma melhora significativa nos salários e no status da carreira.

Assim, o outro aspecto a ser considerado vincula-se à afirmativa de que "la educación de la primera infânciahavia sido manejada por mujeres, no significa que los hombres que entremos tengamos que parecernos o tengamos que niverlarnos a la condición de la mujer". Enquanto destacamos, ao longo do texto, os atravessamentos de gênero em relação à presença do professor do sexo masculino na educação da criança pequena, a afirmação de Humberlet de que o homem por ser mais forte, contribui para que a criança se sinta mais segura e por isso, ele (o professor homem), não se deve nivelar à condição feminina carrega um argumento que segue na contramão da defesa da igualdade de gênero e equidade na profissão docente. Ou seja, se o lugar do professor homem na educação infantil ainda é tido como um tabu - ou atravessamento de gênero - afirmações como essa de Humberlet se mostra prenhe daquilo que o movimento feminista tem combatido ao longo da história que é o androcentrismo.

Em outro momento da entrevista, o professor Humberlet relatou que ao separarem as crianças por sexo, em uma atividade realizada em grupos, tanto ele quanto alguns outros docentes envolvidos nessa atividade, concluíram que, efetivamente, entre os humanos, as diferenças não se estruturam apenas em função do gênero, pois as pessoas são diferentes entre si. Em suaspalavras:

[...] Y descubrimos que efetivamente hay diferencias, que realmente los seres humanos por más que queramos parecernos, no nos parecemos, nos ayudamos, 
podemos compartir muchas cosas, todo lo que usted quiera, pero pensamos, tenemos unos ritmos de aprendizaje diferentes respetados y no quiere decir que uno es mejor que el otro, simple y llanamente somos diferentes (Entrevista concedida em 23/10/2017).

Ao separar as crianças em dois grupos - masculino e feminino - para apurar a percepção de possíveis diferenças, em conformidade com o gênero de cada um deles, evidencia que "a percepção recebe conteúdos da experiência e a sensibilidade organiza racionalmente segundo a forma do espaço e do tempo" (CHAUÍ, 2000, p.97). Dessa maneira, é aceitável que para alcançar o entendimento relacionado às diferenças humanas entre meninos e meninas, seria perfeitamente desnecessário agrupar as crianças por gênero, pois já sabemos que as pessoas são diferentes entre si. Entretanto, como afirma Chauí, organizações como essa "transforma as percepções em conhecimentos intelectuais ou em conceitos" (CHAUÍ, 2000, p.97), o que torna interessante a experiência realizada pelo professor Humberlet e seus colegas. Assim, ao concluir essa atividade, o professor Humberlet percebeu que "las diferencias son importantes para mantener el equilibrio".

Deste modo, ao explicitar essa conclusão, Humberlet nos faz concordar com Chauí (2000, p.154) quando essa autora afirma que o mundo percebido é qualitativo, significativo, estruturado e estamos nele como sujeitos ativos e por isso, damos às coisas percebidas novos sentidos e novos valores, pois as coisas fazem parte de nossas vidas, de nosso mundo.

Tais diferenças ganham centralidade na entrevista e possibilitam buscarmos compreender qual o tratamento dado pelo professor ao corpo das crianças em suas atividades voltadas para o teatro. Utilizando analogias e metáforas, Humberlet destaca que é preciso fazer um trabalho de consciência sobre o corpo. Assim, ele faz com as crianças uma comparação entre o corpo delas e uma arca onde se guarda todos os órgãos dos quais é preciso cuidar. Esta arca guarda um tesouro que é o coração onde estão os sentimentos e as emoções. Ela guarda os pulmões e graças a eles é possível respirar. Há ainda uma quantidade de coisas, de joias, de tesouros e a arca é o nosso próprio corpo. Este corpo é fundamental para seguir vivendo e crescendo, tem a pele, essa coisa estética e formosa que nos veste e que é reflexo da arte. E assim, na concepção desse professor, as crianças começam a cuidar de si e do outro, a proteger-se a valorizar-se, mas antes, é preciso ter consciência do valor que carregam em seu interior.

No Brasil, como dito inicialmente, tem crescido o número de pesquisas que discutem a relação que um professor homem estabelece com os corpos de crianças no 
interior de instituições de Educação Infantil, comumente expressando as dimensões vinculadas a abusos, desconfiança, pedofilia, violência, homossexualidade, dentre outras (SAYÃO, 2005; MONTEIRO e ALTMANN, 2014; SILVA, 2014; LOPES, 2015, ZANETTE, 2018), entretanto, diferentemente dos argumentos que colocam em xeque a idoneidade do professor, como nas pesquisas brasileiras, em relação ao tratamento dispensado aos corpos das crianças, o professor Humberlet relatou a estratégia por ele utilizada para que as crianças reconhecessem a importância em valorizar o próprio corpo e os corpos dos colegas.

O professor Humberlet nada mencionou sobre dificuldades em lidar com os corpos de meninas e meninos, nem sobre pedofilia, abusos, homossexualidade e tantos outros assuntos correlatos. Para ele, a única maneira de uma criança respeitar o seu e o corpo dos outros é quando ela entende "quien soy yo" e quando descobrir que "La otra es como es ella" [com suas próprias singularidades]. Desta maneira, o professor destacou que a criança necessita entender o próprio corpo para saber respeitá-lo e, assim, ao obter esta compreensão, saberá respeitar o corpo do outro. Essa posição é convergente com a ideia de um corpo que opera, simultaneamente, no coletivo e no individual, pois, de acordo com Goellner (2005), o corpo é uma unidade biopolítica e, por isso, "podemos pensar no corpo como algo que se produz historicamente, o que equivale dizer que o nosso corpo só pode ser produto do nosso tempo" e exige de nós, na atualidade, não apenas prazer, mas também disciplina, responsabilidade e dedicação (GOELLNER, 2005, p.40).

\section{GÊNERO - CATEGORIA RELACIONAL: OS PROFESSORES HOMENS NA VISÃO DAS PROFESSORAS}

As duas professoras titulares ${ }^{9}$ das turmas investigadas, Sony e Mary, foram entrevistadas individualmente. De modo mais preciso, ao discorrer sobre a presença de homens no espaço institucional de educação e cuidado das crianças pequenas, a professora Sony destacou algumas precauções sobre as relações que os docentes homens e mulheres - devem estabelecer com as crianças.

$\mathrm{Na}$ condição de pesquisador do sexo masculino, o primeiro autor desse artigo, antes de abordar a questão da presença dos dois professores homens que atuavam na turma em que Sony era a professora titular, apontou as dificuldades para ele próprio que,

${ }^{9} \mathrm{Na}$ Colômbia, denomina-se professoras titulares as docentes que são referências de turmas - no caso desse Instituto Pedagógico Lewis Carroll, todas as professoras titulares eram do sexo feminino. Além dessas professoras, em conformidade com horários pré-estabelecidos, atividades diversificadas são atribuídas a outros professores, como por exemplo, Teatro, Música, Educação Física, dentre outras. 
além de ser do sexo masculino, não dominava integralmente o idioma das crianças que, naquele estágio da pesquisa (final de permanência no campo de pesquisa), já o tratavam como um "velho" conhecido, não poupando abraços, toques corporais e estabelecendo pequenos diálogos. Sony se posicionou da seguintemaneira:

En Colombia se presentan muchas situaciones, por todo lo que há pasado de abusos
y más con los chiquitos, entonces, nada más a nosotras, a las maestras, nos dicen
que no podemos limpiarlos cuando van al baño, que no porque puede el niño decir
que la profesora lo tocó, ya eso se vuelve un problema mayor, porque han pasado
muchas situaciones en muchos colegios y jardines infantiles donde, entonces, entra
ya lo que es toda la parte del abuso. Uno anda prevenida y los padres mucho más,
entonces, también a ellos, a los papás, se les cuenta que van a estar tales personas,
que vienen los practicantes, que vamos a estar acompañados de tales personas,
para que ellos también sepan quién estará ahí, porque personsas ajenas a la
institución podrían decir: bueno, pero ese profesor tiene a todos los niños
abrazados. Por eso, es bueno que estén en espacios más colectivos (Entrevista
concedida em 19/10/2017).

Como se trata de uma instituição de aplicação, em que os estudantes do "bacharelado" fazem algumas práticas pedagógicas nas turmas das crianças, transitavam muitos rapazes e moças pelas duas turmas investigadas. É nesta perspectiva que a professora Sony tece seus comentários sobre o modo de se precaver quanto ao que as crianças podem comentar com os seus pais sobre a presença de "estranhos" no espaço institucional. Por isso, a advertência: "es bueno que estén en espacios más colectivos".

Portanto, é possível inferir que não apenas os homens adultos - seja na condição de professor ou não - no processo de interação com as crianças devem estar em locais visíveis e coletivos, como também os próprios adolescentes, como explicita a professora Sony. Neste sentido, outros aspectos devem ser considerados quando a questão se vincula ao contato corporal com as crianças pequenas ou conforme salientam Campos et al. (1991, p. 54-55):

Referimo-nos à sensualidade que impregna a interação adulto-criança pequena, provinda tanto do contato corpo-a-corpo quanto da importância que assumem indicadores sensoriais: odores, temperatura, sons, etc. apesar de interdito, suspeitar a presença de desejos nessa relação, admite-se mais facilmente essa sensualidade na interação mulher-criança que na homem-criança. É como se a maternidade efetiva ou potencial de qualquer mulher impedisse ou bloqueasse a erotização de suas interações com a criança.

Assim como os demais sujeitos entrevistados, Sony também reconheceu as atribuições próprias do campo da Educação Inicial como afazeres historicamente vinculados ao feminino e vincula, ainda, esses afazeres aos papeis sociais desempenhados pela família: "el pré-escolar hay sólo maestras mujeres, entonces, también ver um hombre es como, hay mamitas y papás!" [expressão de admiração que, 
neste caso, indica surpresa ou espanto]. Para ela, a família entende que as crianças devem estar com as professoras, por isso mesmo - enfatiza - até os cursos de licenciaturas em pedagogia e tudo que se faz na pré-escola, "casi siempre son sólo mujeres".

De igual maneira, Mary - a professora titular da outra turma - antes de falar sobre a presença de professores do sexo masculino na Educação Inicial, retoma a forma de constituição das escolas para crianças em seu país, destacando a relação entre a educação e o cuidado:

[...] antes era sólo jardines asistenciales para el cuidado de los niños, pero ya entendimos que los niños no solo necesitan el cuidado, sino que también necesitan que los desarrollemos integralmente, a eso le apunta la educación infantil, a la protección, en cuanto a sus derechos y uno de sus derechos es la educación (Entrevista concedida em 27/10/2017).

Ao ser indagada sobre a relação dos professores homens com as crianças da sua turma, Mary afirma que:

\begin{abstract}
La relación del sexo masculino con los niños es excelente, a veces los niños pequenos, muy pequenos, de pronto, al ver a los profesores hombres muy altos, por ejemplo, al profe de teatro [referindo-se aoprofessor Humberlet], a veces en la primera clase en la que no estoy con ellos pueden sentir un poco de temor, pero es la primera clase solamente, después de que lo conocen [a Humberlet], después la relacion es excelente con los profesores hombres, tenemos el profesor de música, el profe de teatro, el profe de educación física que son hombres, pero su relación es muy buena con los niños pequeños (Entrevista concedida em 27/10/2017).
\end{abstract}

Ao enfatizar o cuidado como parte da assistência às crianças pequenas, a professora Mary faz alusão a uma dimensão que, em princípio, norteava as ações das instituições de educação infantil em seu país, exatamente como ocorreu no Brasil que, durante muitos anos, manteve a educação infantil vinculada à assistência social. Esse destaque dado pela professora Mary é consonante também com o pensamento dos demais docentes entrevistados: "La relación del sexo masculino com los niños es excelente...", ao afirmar que somente na primeira aula, sem a presença da professora, é que as crianças sentem um pouco de temor e após esse primeiro contato, a relação fica excelente, podemos entender, por meio dessa resposta que há por parte das crianças um temor momentâneo, no entanto, tal assertiva pode nem estabelecer relação diretamente com o fato de se tratar de um homem na docência, uma vez que é comum as crianças "estranharem", em um primeiro contato as pessoas desconhecidas. Sendo assim, independentemente do gênero, as crianças podem ser acometidas por "insegurança" e não por medo. Ou seja, podemos inverter essa lógica e indagar: mas será que as crianças 
nas primeiras "aulas" também não sentem temor das professoras? Em outro estudo sobre a presença de homens na educação infantil, o primeiro autor deste artigo, (RAMOS, 2011) denomina de "estágio comprobatório", esse período de adaptação que o próprio professor necessita, no espaço institucional, para ser aprovado pela comunidade escolar. Ou seja, entendemos que é intrínseco ao trabalho - seja para professores ou professoras - um período mínimo de interação com as crianças para estabelecer uma relação menos "temerosa" entre os adultos e as crianças.

\section{CONSIDERAÇÕES FINAIS}

No Brasil, a educação da criança em creches e pré-escolas por ser uma atividade que nasceu da organização e das lutas de mulheres, foi - e continua sendo, atualmente - uma área de atuação majoritariamente feminina. Apesar da lenta e progressiva inserção de profissionais do sexo masculino nessa etapa da educação, é necessário considerar que os avanços obtidos no campo da política de Educação Infantil, é resultado das lutas e organização da sociedade, em especial, dos movimentos feministas e de mulheres trabalhadoras. Os ordenamentos legais, surgidos a partir da década de 1980 apenas incorporou a si, algo que já estava presente nos movimentos sociais, uma vez que a sociedade sempre atribuiu importância à educação infantil em espaços institucionais e a legislação apenas respondeu às enormes pressões dos diferentes movimentos sociais, dentre elas as lutas das mulheres por creches (RAMOS, 2011, p.44).

Neste sentido, ao dialogarmos com essa progressiva inserção de professores homens nesta etapa inicial da educação, é necessário dialogar com a permanência deles nesses espaços institucionais. O material empírico produzido por meio das entrevistas com os professores e as professoras da instituição colombiana, nos faz perceber que há, ainda, muitas reflexões sobre o lugar ocupado por esses sujeitos em creches e préescolas. Sendo assim, a percepção dos próprios professores masculinos sobre o exercício da docência nesses espaços de educação e cuidados de crianças aponta a existência de contradições, tensionamentos e ambivalências.

Dentre as inúmeras contribuições oriundas das entrevistas com os quatro professores colombianos para a compreensão dos papeis desenvolvidos por homens em suas atividades docentes, destacamos o fato de que atribuir aos docentes do sexo masculino a função de substituto paterno, é retomar o mesmo caminho, historicamente traçado, que contribuiu para a precarização da profissão, ao associar as atribuições relacionadas ao cuidado de crianças às tarefas domésticas e à maternagem. Tal 
entendimento, além de servir como baluarte para a precarização do trabalho, serve também para impulsionar interesses escusos com tendência à desvalorização de uma carreira já bastante desvalorizada, pelo menos em sociedades como as dos países latinoamericanos em que a profissão de educador, em geral, e de educadores infantis, em particular, não está amplamente associada ao sucesso profissional, à melhoria da qualidade de vida ou à ascensão social .

Conforme percebido nas entrevistas, os próprios trabalhadores e trabalhadoras em educação retroalimentam essa ideia quando avaliam ser possível "encarnar" a figura do pai, retrocedendo, assim, em aspectos relevantes relacionados à função social de creches e pré-escolas, seja na Colômbia, no Brasil ou qualquer outro país. Para avançarmos em relação à presença de professores do sexo masculino na Educação Infantil, é necessária uma concepção mais abrangente da função docente que possibilite compreender que o desenvolvimento da criança é uma tarefa tanto de professoras quanto de professores, sem distinção de sexo ou gênero. Entendemos que procedendo desta maneira, poderemos vislumbrar, de modo mais efetivo, a construção de uma sociedade inclusiva e predisposta a lutar pelo respeito à diversidade e à diferença.

\section{REFERÊNCIAS}

BRAILOVSKY, Daniel. "Los Muy Señoritos": la profesión docente en la experiencia de los maestros jardineiros. In-fan-cia latinoamericana Revista digital de la asociación de maestros Rosa Sensat- Ago. 2013. Disponível em:

latinoamericana@revistainfancia.org, acesso em 05 mai. 2020.

BRASIL. Lei de Diretrizes e Bases da Educação Nacional. Brasília, 1996.

BRASIL. Base Nacional Comum Curricular. Brasília: MEC, 2017. Disponível em: http://basenacionalcomum.mec.gov.br/images/BNCC_20dez_site.pdf. Acesso em: 22 de maio de 2020.

BUSS-SIMÃO, Márcia. Relações sociais em um contexto de educação infantil: um olhar sobre a dimensão corporal na perspectiva de crianças pequenas. 2012. $312 \mathrm{f}$. Tese (Doutorado em Educação) - Universidade Federal de Santa Catarina, Florianópolis, 2012.

CARVALHO, Marília Pinto de. No coração da sala de aula: gênero e trabalho docente nas séries iniciais. São Paulo: Xamã, 1999.

CHAUÍ, Marilena. Convite à Filosofia. São Paulo: Ed. Ática, 2000. 
CAMPOS, Maria Malta; GROSBAUM, Marta W.; PAHIM, Regina; ROSEMBERG,Fúlvia. Profissionais de creche. Cadernos CEDES: educação pré-escolar:desafios e alternativas, Campinas, n. 9, 1991.

COLOMBIA. Ley general de educación. Congreso de la República de Colombia. Ley 115 (de 8 de fev. de 1994).

COLOMBIA. Ministerio de la Educación Nacional. Sentido de la educación inicial. Serie de orientaciones pedagógicas para la educación inicial en el marco de la atención integral. Documento no 20, 2014.

CONNELL, Robert W. Políticas da masculinidade. In: Educação e Realidade. Vol. 20 (2), jul/dez. 1995, p. 185-206.

CRUZ, Elisabete Franco. "Quem leva o nenê e a bolsa?": o masculino na creche. In: ARILHA, M.; RIDENTI, S. G. U.; MEDRADO, B. (Org.). Homens e masculinidades: outras palavras. São Paulo: ECOS, Ed. 34, p. 235-258, 1998.

FERREIRA, José Luiz. Homens ensinando crianças: continuidades-descontinuidades nas relações de gênero na escola rural. Tese (Doutorado em Educação). João Pessoa, UFPB, 2008.

JUNQUEIRA, Rogério Diniz. "Temos um problema em nossa escola: um garoto afeminado demais". Pedagogia do armário e currículo em ação. Universidade Federal de Uberlândia. Revista Educação e Políticas em Debate, v. 4, n²- ago./dez. 2015.

LOPES, Elsa Santana dos Santos. A presença masculina na creche: estariam os educadores homens fora de lugar? 2015. $160 \mathrm{f}$. Tese (Doutorado) - Curso de Doutorado em Educação, Universidade Católica de São Paulo, São Paulo.

LOURO, Guacira Lopes. O corpo educado: pedagogias da sexualidade. Guacira Lopes Louro (org.). Tradução dos artigos: Tomaz Tadeu da Silva. Belo Horizonte: Autêntica, 1999.

LOURO, Guacira Lopes; FELIPE, Jane; GOELLNER, Silvana Vilodre. Corpo, gênero e sexualidade: um debate contemporâneo na educação. GOELLNER, Silvana Vilodre. In: A produção cultural do corpo. 'Petrópolis: Editora Vozes, 2005.

LÜDKE, Menga, ANDRÉ, Marli E. D. A. Pesquisa em educação: abordagens qualitativas. Rio de Janeiro: E.P.U., 2014.

MONTEIRO, Mariana Kubilius; ALTMANN, Helena. Homens na Educação Infantil: olhares de suspeita e tentativa de segregação. Cadernos de Pesquisa, v.44, no 153, p.720-741, jul./set.2014.

MORENO, Rodrigo Ruan Merat. Professores homens na Educação Infantil do município do Rio de Janeiro: vozes, experiências, memórias e histórias. Pontifícia Universidade Católica do Rio de Janeiro. Dissertação de mestrado. 2017. 
PEREIRA, Maria Arlete Bastos. Professor homem na educação infantil: a construção de uma identidade. 2012. 162 f. Dissertação (Mestrado) - Curso de Filosofia, Letras e Ciências Humanas, Universidade Federal de São Paulo, Guarulhos.

RAMOS, Joaquim. Análise contrastiva das estratégias de resistência das crianças frente à regulação dos adultos em uma instituição de educação infantil brasileira e duas colombianas. Belo Horizonte, 2018. Tese de doutorado, Universidade Federal de Minas Gerais. $408 \mathrm{f}$.

\section{RAMOS, Joaquim. Gênero na Educação Infantil:relações (im)possíveis para professores homens.Jundiaí: Paco Editorial, 2017. 176 p.}

RAMOS, Joaquim. Um estudo sobre os professores homens da educação infantil e as relações de gênero na rede municipal de Belo Horizonte- MG. Belo Horizonte, 2011. Dissertação (mestrado em educação) Pontifícia Universidade Católica de Minas Gerais. 139f.

RUIZ, Alexander y PRADA, Manuel. (2020) Didáctica de la fantasia. La educación del niño como sujeto de derechos. Bogotá. - Medellín: Universidad Pedagógica Nacional - La Carreta editores.

SAYÃO, Débora Thomé. Relações de gênero e trabalho docente na Educação Infantil: um estudo de professores em creche. 2005. 273 f. Tese (doutorado) Universidade Federal de Santa Catarina: PPGE, Florianópolis, 2005.

SILVA, Claudionor Renato da; VELOSO, Luana Alves Porto. Desafios do professor homem na Educação Infantil: um debate a partir do estágio em Pedagogia. Revista: ItinerariusReflectionis. Universidade Federal de Goiás, vol. 14, nº 1, 2018.

SILVA, Peterson Rigato da. Não sou tio, nem pai, sou professor! A docência masculina na educação infantil. 2014. 222 f. Dissertação (Mestrado) - Curso de Educação, Universidade Estadual de Campinas, Campinas.

SILVA, Tuéli Fonseca da; RABELO, Giani. Gênero e educação: um panorama das pesquisas acadêmicas no Brasil a respeito da docência masculina na Educação Infantil. Revista: Saberes Pedagógicos, Criciúma, v. 3, nº1, janeiro/junho 2019.Curso de Pedagogia- UNESC.

SILVA, Walter Lúcio da. Homens que educam: desafios do nosso tempo. Campina Grande: Universidade Estadual da Paraíba, 2013.

SOUSA, José Edilmar de. Homem na docência com crianças pequenas: o olhar das crianças de um centro de Educação Infantil. 37a Reunião Nacional da ANPEd - 04 a 08 de outubro de 2015, UFSC - Florianópolis.

ZANETTE, Jaime Eduardo. Coordenação pedagógica na educação infantil e as (im)possibilidades de uma rede (in)formativa sobre gênero e sexualidade. $140 \mathrm{f}$. Disseração (Mestrado), Faculdade de Educação da Universidade Federal do Rio Grande do Sul, Porto Alegre, 2018. 


\section{NOTAS}

PROFESSORES HOMENS NA EDUCAÇÃO INICIAL: UM ESTUDO DE CASO EM UMA INSTITUIÇÃO DE EDUCAÇÃO INFANTIL COLOMBIANA ${ }^{10}$

Male teachers in Early Education: a case study in a Colombian Early Childhood Education

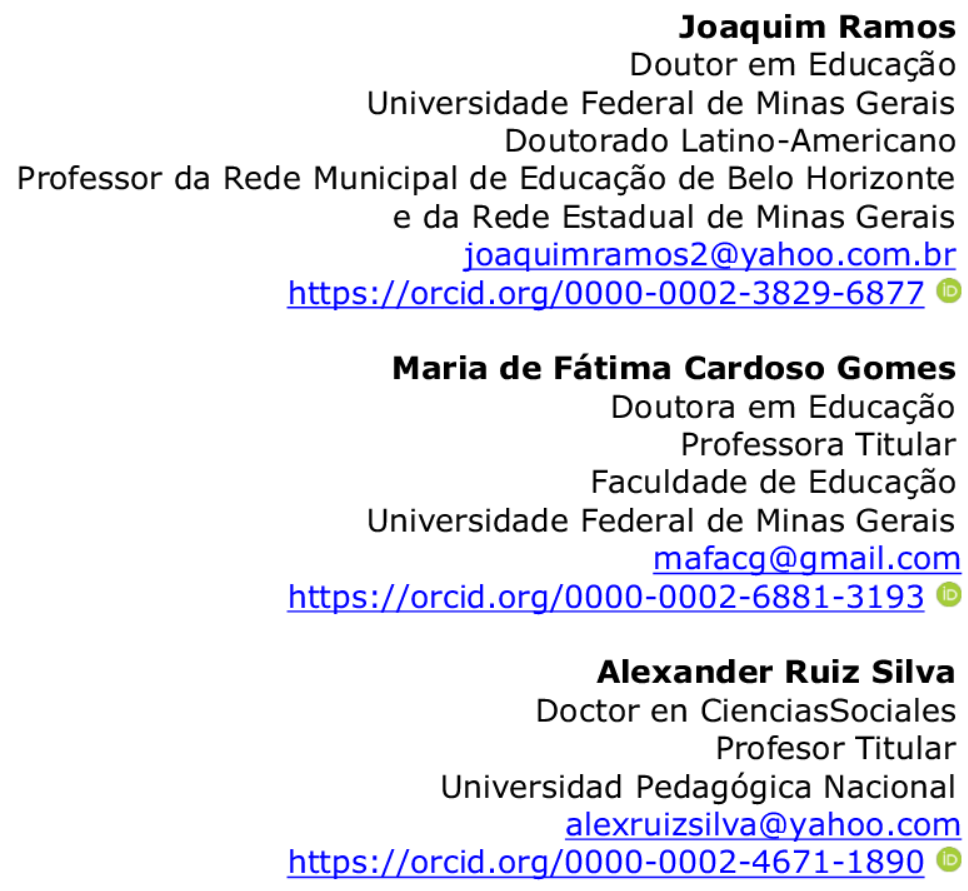

Endereço de correspondência do principal autor

Rua Três, 85 - Bairro Diamante - Belo Horizonte/MG CEP.: 30660-132

\section{AGRADECIMENTOS}

Inserir os agradecimentos a pessoas que contribuíram com a realização do manuscrito.

\section{CONTRIBUIÇÃO DE AUTORIA}

Concepção e elaboração do manuscrito: J. Ramos

Coleta de dados: J. Ramos

Análise de dados: J. Ramos, M. F. C. Gomes

Discussão dos resultados: J. Ramos, M. F. C. Gomes, A. R. Silva

Revisão e aprovação: J. Ramos, M. F. C. Gomes, A. R. Silva

\section{CONJUNTO DE DADOS DE PESQUISA}

Todo o conjunto de dados que dá suporte aos resultados deste estudo foi publicado no próprio artigo.

\section{FINANCIAMENTO}

Agradecemos ao CNPq pela concessão de bolsa por todo o período de realização do Doutorado.

\section{CONSENTIMENTO DE USO DE IMAGEM}

Não se aplica.

\section{APROVAÇÃo de COMITÊ DE ÉTICA EM PESQUISA}

O COEP - Comitê de Ética em Pesquisa da UFMG aprovou, em 06 de abril de 206, o projeto de pesquisa do qual resultou o presente artigo PROJETO: CAAE - 5264663815.2,0000.5149

10 Os termos Educação para a Primeira Infância e Educação Inicial são nomenclaturas utilizadas na Colômbia para se referir à educação das crianças de zero a cinco anos de idade, no campo da política nacional "De cero a siempre". 


\section{CONFLITO DE INTERESSES}

Não se aplica.

LICENÇA DE USO - uso exclusivo da revista

Os autores cedem à Zero-a-Seis os direitos exclusivos de primeira publicação, com o trabalho simultaneamente licenciado sob a Licença Creative Commons Attribution (CC BY) 4.0 International. Esta licença permite que terceiros remixem, adaptem e criem a partir do trabalho publicado, atribuindo o devido crédito de autoria e publicação inicial neste periódico. Os autores têm autorização para assumir contratos adicionais separadamente, para distribuição não exclusiva da versão do trabalho publicada neste periódico (ex.: publicar em repositório institucional, em site pessoal, publicar uma tradução, ou como capítulo de livro), com reconhecimento de autoria e publicação inicial neste periódico.

PUBLISHER - uso exclusivo da revista

Universidade Federal de Santa Catarina. Núcleo de Estudos e Pesquisas da Educação na Pequena Infância - NUPEIN/CED/UFSC. Publicação no Portal de Periódicos UFSC. As ideias expressadas neste artigo são de responsabilidade de seus autores, não representando, necessariamente, a opinião dos editores ou da universidade.

EDITORES - uso exclusivo da revista Márcia Buss-Simão e Kátia Agostinho.

HISTÓRICO - uso exclusivo da revista

Recebido em: 16-07-2020 - Aprovado em: 23-08-2020 